\title{
Determination of oxygenated and native polycyclic aromatic hydrocarbons in urban dust and diesel particulate matter standard reference materials using pressurized liquid extraction and LC-GC/MS
}

\author{
Trifa M. Ahmed • Christoffer Bergvall • Magnus Åberg • \\ Roger Westerholm
}

Received: 14 July 2014 /Revised: 22 October 2014 / Accepted: 28 October 2014 / Published online: 14 November 2014

(C) The Author(s) 2014. This article is published with open access at Springerlink.com

\begin{abstract}
The objective of this study was to develop a novel analytical chemistry method, comprised of a coupled highperformance liquid chromatography-gas chromatography/ mass spectrometry system (LC-GC/MS) with low detection limits and high selectivity, for the identification and determination of oxygenated polycyclic aromatic hydrocarbons (OPAHs) and polycyclic aromatic hydrocarbons (PAHs) in urban air and diesel particulate matter. The linear range of the four OPAHs, which include 9,10-anthraquinone, $4 \mathrm{H}$ cyclopenta[def]phenanthrene-4-one, benzanthrone, and 7,12benz[a]anthraquinone, was $0.7 \mathrm{pg}-43.3 \mathrm{ng}$ with limits of detection (LODs) and limits of quantification (LOQs) on the order of $0.2-0.8$ and $0.7-1.3 \mathrm{pg}$, respectively. The LODs in this study are generally lower than values reported in the literature, which can be explained by using large-volume injection. The recoveries of the OPAHs spiked onto glass fiber filters using two different pressurized liquid extraction (PLE) methods were in the ranges of $84-107$ and $67-110 \%$, respectively. The analytical protocols were validated using the following National Institute of Standards and Technology standard reference materials: SRM 1649a (Urban Dust), SRM 1650b (Diesel Particulate Matter), and SRM 2975 (Diesel Particulate Matter, Industrial Forklift). The measured mass fractions of the OPAHs in the standard reference materials (SRMs) in this present study are higher than the values from the literature, except for benzanthrone in SRM 1649a (Urban
\end{abstract}

Electronic supplementary material The online version of this article (doi:10.1007/s00216-014-8304-8) contains supplementary material, which is available to authorized users.

T. M. Ahmed $\cdot$ C. Bergvall $\cdot$ M. Åberg $\cdot$ R. Westerholm $(\bowtie)$

Department of Analytical Chemistry, Arrhenius Laboratory,

Stockholm University, 10691 Stockholm, Sweden

e-mail: roger.westerholm@anchem.su.se
Dust). In addition to the OPAHs, 44 PAHs could be detected and quantified from the same particulate extract used in this protocol. Using data from the literature and applying a twosided $t$ test at the $5 \%$ level using Bonferroni correction, significant differences were found between the tested PLE methods for individual PAHs. However, the measured mass fractions of the PAHs were comparable, similar to, or higher than those previously reported in the literature.

Keywords OPAHs · PAHs · PLE · SRM 1649a · SRM 2975 . SRM $1650 \mathrm{~b}$

\section{Introduction}

A vast body of scientific studies has shown associations between human exposure to urban air particulate matter (PM) pollution and severe health outcomes such as lung cancer, diseases of the respiratory and cardiovascular systems, premature mortality, and an increase in infant mortality [1-4]. The risks posed may be substantial; estimates from the Clean Air for Europe (CAFE) framework program indicate that approximately 350,000 premature deaths per year in the European Union can be attributed to exposure to PM [5]. A major source of PM in urban environments is motorized vehicles. The PM emitted from diesel-powered vehicles is especially considered to contribute to general health hazards $[1,3,6-8]$, and in addition, diesel exhaust is classified as being carcinogenic to humans (Group 1) by the International Agency for Research on Cancer (IARC) [9]. However, the link between exposure to air PM pollution and adverse health effects has not yet been fully established, and consequently, it is important to characterize the chemical contents of air and 
diesel-derived PM [1, 3, 7]. Polycyclic aromatic hydrocarbons (PAHs) constitute a group of ubiquitous environmental pollutants present in air PM derived from different sources, and they are considered to play an important part in the adverse health outcomes due to PM exposure [6, 10]. Benzo[a]pyrene $(\mathrm{B}[\mathrm{a}] \mathrm{P})$ is the only PAH currently classified as a human carcinogen, while many other PAHs are classified as possibly or probably carcinogenic (Groups 2A and 2B) to humans by the IARC [9]. In addition to cancer, PAHs have also been linked to reproductive and cardiovascular diseases $[9,10]$. A group of less-studied PAH derivatives are oxygenated polycyclic aromatic hydrocarbons (OPAHs), which have recently been noted as being particularly reactive compounds with the potential of causing adverse biological effects. Due to their direct mutagenic potency, OPAHs may be more toxic to humans compared to their parent PAHs [11, 12]. OPAHs have higher molecular weights and lower vapor pressures than their parent PAHs [13], and thus, they have a higher tendency to be absorbed to PM in the atmosphere compared to their parent PAHs [14]. However, in a study on ambient air particles, it was shown that the low molecular weight OPAHs, naphthoquinone and anthraquinone, were more highly distributed in the gas phase [15]. In addition to their presence in the atmosphere, OPAHs have also been identified in PM from diesel and gasoline exhaust [16, 17]. PM from the atmosphere and from vehicle exhaust is a complex chemical matrix with OPAHs present at trace levels. Consequently, for methods aimed at the determination of OPAHs, there are high demands on both the selectivity and detection limits. Various different approaches have been used in analyzing OPAHs, which have been recently reviewed by Walgraeve and co-workers [18]. Typically, the OPAHs associated with PM are solvent extracted using various techniques such as Soxhlet extraction [19], ultrasonically assisted extraction [20,21], supercritical fluid extraction [22], and pressurized liquid extraction (PLE) [23-25]. PLE has been shown to give an equivalent or higher extraction efficiency compared to Soxhlet extraction for PAHs from air and diesel PM standard reference materials (SRMs) and recently for OPAHs from a diesel PM SRM [26].

Chemically complex extracts of PM usually require one or several cleanup steps prior to the final analysis. Generally, sample cleanup is labor intensive and time consuming, and advantages could be gained by the online coupling of the sample pre-treatment and the analysis. Increasing the degree of automation in analytical protocols reduces manual sample handling and reduces the risk of errors due to cross contamination and analyte losses.

An alternative to manual cleanup and subsequent gas chromatography (GC) analysis is the online coupling of HPLC and GC, which has been extensively reviewed by Hyötyläinen and Riekkola [27]. Online HPLC-GC combines the flexible and selective cleanup capabilities of HPLC with the high peak resolution of GC. By using large-volume injection (LVI), a major part of the sample can be injected, thereby lowering the detection limits in comparison with traditional GC injection techniques where only a small part of the sample $(\sim 1 \mu \mathrm{l})$ is introduced into the GC. Furthermore, the HPLC separation can be easily monitored using a UV detector allowing for precise fractions to be transferred to the GC.

The coupling of liquid chromatography (LC) to GC/mass spectrometry (MS) for partial sample cleanup, separation, and detection has been successfully applied for the analysis of PAHs in environmental matrices [28, 29].

The aim of the present study was to evaluate and optimize a methodology comprised of PLE, initial sample cleanup using solid-phase extraction (SPE), and automated cleanup, separation, and detection using $\mathrm{LC}-\mathrm{GC} / \mathrm{MS}$ for the determination of the OPAHs in air and diesel PM.

\section{Experimental}

\section{Chemicals and solvents}

The solvents used in this present study were toluene, methanol, hexane, methyl tert-butyl ether (HPLC grade, Rathburn Chemicals Ltd, UK), ethanol (absolute, Ph. Eur., VWR International S.A.S, Fontenay-sous-Bois, France), and anhydrous dodecane ( $>99 \%$, Sigma-Aldrich, St. Louis, MO, USA).

The OPAH calibration standard solutions used for quantification and identification consisted of perdeuterated anthraquinone- $\mathrm{D}_{8}\left(\mathrm{AQ}-\mathrm{D}_{8}\right) 99.4 \%$ as an internal standard, 9,10-anthraquinone (ANQ) $>99.5 \%, 4 H$-cyclopenta[def]phenanthren-4one (CCPQ) $>99 \%$, benzanthrone (BAQ) $>98.5 \%$, and 7,12benz[a]anthraquinone (BaAQ) $97.5 \%$ dissolved in toluene, and they were all purchased as solutions from Chiron AS (Trondheim, Norway). Hexane was initially used as the diluent, but it was observed that the OPAHs precipitated, and therefore, toluene was selected for the dilutions. Perylene (see Electronic Supplementary Material (ESM) Table S1) was used as a volumetric internal standard for the recovery experiments on SPE, and Cor- $\mathrm{D}_{12}$ was added as a volumetric internal standard to the second extracts from each sample for quantitative analyses of the PLE extracts. AQ- $\mathrm{D}_{8}$ was used as a volumetric internal standard for the determination of the recoveries for the spiked PLE filter experiments. A list of the PAHs and internal standards used in this study along with their abbreviations and suppliers is given in ESM Table S1 in the supporting information. All of the standard solutions were stored in a freezer at $-18{ }^{\circ} \mathrm{C}$ prior to use. Before use, the standard solutions were ultrasonicated at room temperature for $10-15 \mathrm{~min}$. Furthermore, laboratory UV filters (LF 101 yellow, Bellialite, Sweden) were used for covering both the windows and light sources in the laboratory to eliminate the potential breakdown of the analytes [30]. 
Standard reference materials

The standard reference materials used in this present study were the following: SRM 1649a (Urban Dust) [31], SRM 1650b (Diesel Particulate Matter) [32], and SRM 2975 (Diesel Particulate Matter, Industrial Forklift) [33], all of which were purchased from the National Institute of Standards and Technology (NIST, Gaithersburg, MD, USA).

Pressurized liquid extraction of OPAHs and PAHs

Three replicate samples of each individual SRM, which corresponded to $10 \mathrm{mg}$ of SRM 1649a, $20 \mathrm{mg}$ of SRM 1650b, and $20 \mathrm{mg}$ of SRM 2975, were weighed on glass microfiber filters ( $\mathrm{GF} / \mathrm{C}, \varnothing=47 \mathrm{~mm}$, Whatman International Ltd, England) using an analytical balance with a precision of $\pm 0.001 \mathrm{mg}$. The filters were inserted into the extraction cells, and the following perdeuterated internal standards were added: AQ- $\mathrm{D}_{8}$, Phe- $\mathrm{D}_{10}$, Pye- ${ }_{10}, B[a] A-D_{12}, B[a] P-D_{12}, B$ [ghi]P-D ${ }_{12}$, and DB[ai]P-D 14 (see ESM Table 1S for the abbreviations).

The PM samples were extracted using an accelerated solvent extraction system (ASE 200, Dionex Corporation, Sunnyvale, CA, USA). Three different extraction procedures, i.e., E1, E2, and E3, were employed, and the extraction parameters used are shown in Table 1. To investigate the efficiency of the extraction procedure, each sample was extracted an additional time using the same extraction parameters used in the first extraction.

\section{Isolation of OPAHs and PAHs}

The PLE extracts were concentrated to approximately $5 \mathrm{ml}$ under a gentle gas stream of nitrogen gas while being heated to $60{ }^{\circ} \mathrm{C}$ in a water bath (TurboVap ${ }^{\circledR} \mathrm{LV}$ evaporator, Zymark, Hopkinton, MA, USA). The concentrated extracts were then transferred to disposable test tubes and evaporated further to volumes of approximately $0.5 \mathrm{ml}$. Silica SPE cartridges (100 mg Isolute, IST, UK) were conditioned with $3 \mathrm{ml}$ of hexane prior to use. The concentrated extracts were then added onto the conditioned SPE cartridges, and the test tubes were rinsed with an additional $0.5 \mathrm{ml}$ aliquot of toluene, which was also added onto the SPE cartridge. Subsequently, the analytes were eluted with $1.5 \mathrm{ml}$ of toluene into a disposable test tube. This fraction was then evaporated to approximately $0.5 \mathrm{ml}$ using a very gentle nitrogen stream, and it was then divided into two aliquots, which were subsequently transferred into two $300 \mu \mathrm{l}$ microvials. One vial was directly used for OPAH analysis, while the second extract was further reduced to approximately $0.1 \mathrm{ml}$, diluted with hexane to approximately $0.3 \mathrm{ml}$, and analyzed for PAHs.

\section{LC-GC/MS analysis}

The hyphenated online LC-GC/MS system used for the separation and detection of OPAHs and PAHs consisted of a CMA/ 200 microsampler (CMA Microdialysis AB, Sweden), an HPLC pump (Varian Inc, Palo Alto, CA, USA), a UV detector (SPD-6A, Shimadzu, Japan), and a normal phase LC column (Nucleosil $100-5 \mathrm{NO}_{2} 124 \times 4.6 \mathrm{~mm}, 5 \mu \mathrm{m}$ ). The GC/MS system consisted of an Agilent $6890 \mathrm{~N}$ gas chromatograph (Agilent Technologies, Palo Alto, CA, USA) with an Agilent 5973N MSD (Agilent Technologies). The LC column was used as a cleanup step for removing alkanes and monoaromatic compounds using the back flush technique. The cleaned-up PAH and OPAH fraction was transferred online through a transfer line to the programed temperature vaporizer (PTV) GC injector. The PTV was operated in the solvent vent mode in order to evaporate the LC effluent. This system allows for automated sample cleanup, and LVI has previously been used for PAH analysis; a description of the system setup and operation can be found outlined in detail elsewhere [28, 29]. Operation of the LC-GC/MS system for PAH analysis was performed in accordance with the parameters outlined by Sadiktsis et al. [34]. Furthermore, for the PAHs determined in this study, details on the calibration data, such as the linear range and coefficients of determination from the calibration curves, LODs, and LOQs, have recently been reported in detail [34].

The same $\mathrm{LC}-\mathrm{GC} / \mathrm{MS}$ method was used for the analysis of OPAHs except that the LC mobile phase was changed to a mixture of hexane and methyl tert-butyl ether $(8: 2, v / v)$ with $0.1 \%$ dodecane added, and the time for reversing the flow through the LC column was adjusted depending on the retention time for $\mathrm{AQ}-\mathrm{D}_{8}$. The large injection volume is a back flush peak from the LC column monitored using the UV detector to transfer most of the part of interest onto the $\mathrm{GC} /$

Table 1 Pressurized liquid extraction parameters used in this study

\begin{tabular}{llllllll}
\hline Extraction method & $\begin{array}{l}\text { Temperature } \\
\left({ }^{\circ} \mathrm{C}\right)\end{array}$ & $\begin{array}{l}\text { Pressure } \\
(\mathrm{MPa})\end{array}$ & $\begin{array}{l}\text { Preheat time } \\
(\mathrm{min})\end{array}$ & $\begin{array}{l}\text { Static cycles } \\
\text { analytical extraction }\end{array}$ & $\begin{array}{l}\text { Static time } \\
(\mathrm{min})\end{array}$ & $\begin{array}{l}\text { Flush volume } \\
(\%)\end{array}$ & $\begin{array}{l}\text { Extraction } \\
\text { solvent }\end{array}$ \\
\hline E1 & 200 & 20.6 & 3 & 5 & 30 & 5 & 30 \\
E2 & 200 & 13.8 & No & 3 & 30 & 30 & Tol:MeOH (9:1) \\
E3 & 200 & 13.8 & No & 3 & Tol & Tol \\
\hline
\end{tabular}

Tol toluene, $\mathrm{MeOH}$ methanol 
MS ( $\geq 95 \%$ for PAHs and $\geq 91 \%$ for OPAHs). The MS system was set to acquire data in the selected ion monitoring (SIM) mode. The molecular ion and two analyte-specific fragments were monitored for each OPAH (see Table 2). The peak identities of the OPAHs in the SRM samples were confirmed by the retention times and relative ion ratios compared to the standard solutions. Concentrations of the PAHs and OPAHs in the SRM samples were calculated using the peak areas of the most abundant ions (see Fig. 1) and the relative response factors established from the calibration curves. Glass microfiber filters served as method blanks for the OPAHs and PAHs and were treated in the same manner as the samples throughout the entire analytical procedure.

\section{Statistical significance}

The measured mass fractions were compared for statistically significant differences using two-sided $t$ tests at the $5 \%$ level with Bonferroni correction. The Bonferroni correction used $n=$ number of analytes for which the method comparison was made. Typically, this number ranged from 4 to 44 depending on the SRM and whether the targeted analytes were OPAHs or PAHs. The methods were also compared for systematical differences, e.g., that the concentrations of all of the analytes are consistently lower using one extraction method compared to another, by testing if the distribution showed deviates from what can be expected from a binomial distribution with equal probabilities for the two outcomes.

\section{Results and discussion}

Sample preparation

Three different PLE procedures were used in this study for extracting the OPAHs and PAHs from the SRMs, and details

Table 2 Silica SPE recoveries (mean percentage) of four replicate experiments, coefficient of determination for the linear calibration curves using seven-point calibrations on the LC-GC/MS system, and ions selected for the SIM method

\begin{tabular}{|c|c|c|c|c|c|}
\hline \multirow{2}{*}{$\begin{array}{l}\text { Quinone } \\
\text { standards }\end{array}$} & \multirow{2}{*}{$\begin{array}{l}\text { \% Mean } \\
\text { (STD) }\end{array}$} & \multirow[t]{2}{*}{$R^{2}$} & \multicolumn{3}{|l|}{$m / z$} \\
\hline & & & $\begin{array}{l}\text { Molecular } \\
\text { ion }\end{array}$ & $\begin{array}{l}\text { First } \\
\text { fragment }\end{array}$ & $\begin{array}{l}\text { Second } \\
\text { fragment }\end{array}$ \\
\hline AQ-D 8 & $83.4(3.2)$ & 0.995 & 216 & 188 & 160 \\
\hline AQ & $89.3(3.7)$ & 0.995 & 208 & 180 & 152 \\
\hline 4HCPPQ & $107.3(5.2)$ & 0.996 & 204 & 176 & 150 \\
\hline BAQ & $87.0(4.8)$ & 0.992 & 230 & 202 & 174 \\
\hline $\mathrm{BaAQ}$ & $87.4(6.2)$ & 0.987 & 258 & 230 & 202 \\
\hline
\end{tabular}

STD standard deviation on the PLE methods are presented in Table 1. Extraction procedure E1 is an exhaustive extraction protocol previously developed by our research group [35], and it has previously been used for the determination of PAHs in diesel SRMs [34, 36], whereas extraction procedures E2 and E3 are adopted from a recent paper from NIST using PLE for the extraction of PAHs and nitro PAHs from air and diesel PM SRMs [36]. Recoveries using the two most exhaustive extraction methods, E1 and E3, were calculated by spiking glass microfiber filters with a standard mixture of the OPAHs (Table 3). The results show that the two extraction methods recover between 67 and $110 \%$ of the four OPAHs, as is shown in Table 3. Higher recoveries and lower standard deviations were obtained with the less-exhaustive method E3 compared to method E1 (Table 3). These results correspond with recent studies using PLE [24, 37]. Mirivel and co-workers determined the PLE recoveries of various OPAHs (including BAQ and BaAQ) spiked onto filters to be in the order of 79-107 \% (PLE with methanol and one 8-min static cycle at $100{ }^{\circ} \mathrm{C}$ ) [24], and Walgraeve and co-workers obtained recoveries of $99 \pm$ $4 \%$ and $101 \pm 4 \%$ for BAQ at ambient temperature and at $40{ }^{\circ} \mathrm{C}$, respectively (PLE with ethyl acetate and three 5-min static cycles). The corresponding recoveries for BaAQ were reported to be $110 \pm 14 \%$ and $95 \pm 3 \%$ at ambient air temperature and $40{ }^{\circ} \mathrm{C}$, respectively. The somewhat lower extraction recovery obtained for BaAQ compared to the data presented by Walgraeve and co-workers could be a result of the higher extraction temperature and longer extraction time used in the present study. Although no significant difference in the extraction recovery of BaAQ was obtained by Walgraeve and co-workers at ambient temperature compared with that at $40^{\circ} \mathrm{C}$, the authors suggest that the lower extraction recoveries and higher standard deviations obtained for other OPAHs such as benzo[a]pyrene-4,5-dione, chrysene-5,6-dione, and phenanthrene-9,10-dione at $40{ }^{\circ} \mathrm{C}$ compared with those at ambient temperature could be a result of thermal degradation [37]. Additionally, Lintelmann and co-workers found low extraction recoveries $(<80 \%)$ of OPAHs spiked onto filters when using PLE with toluene, methanol, or hexane/acetone at temperatures $\leq 100{ }^{\circ} \mathrm{C}$, which the authors attributed to degradation or chemical reaction processes [38]. However, none of the OPAHs used in our present study were investigated. Consequently, the lower extraction recoveries and higher standard deviations found in this study for $\mathrm{BaAQ}$ when using extraction procedure $\mathrm{E} 1$, as shown in Table 3, could be due to having $10 \%$ methanol and/or E1 being more exhaustive than E3 (the use of five extraction cycles in E1 compared to the use of three extraction cycles in E3).

Initially, hexane was used as the solvent for eluting the OPAHs from the SPE cartridges using a methodology previously reported for PAHs [27, 28]. However, applying this scheme for the OPAHs resulted in poor analyte recoveries, 

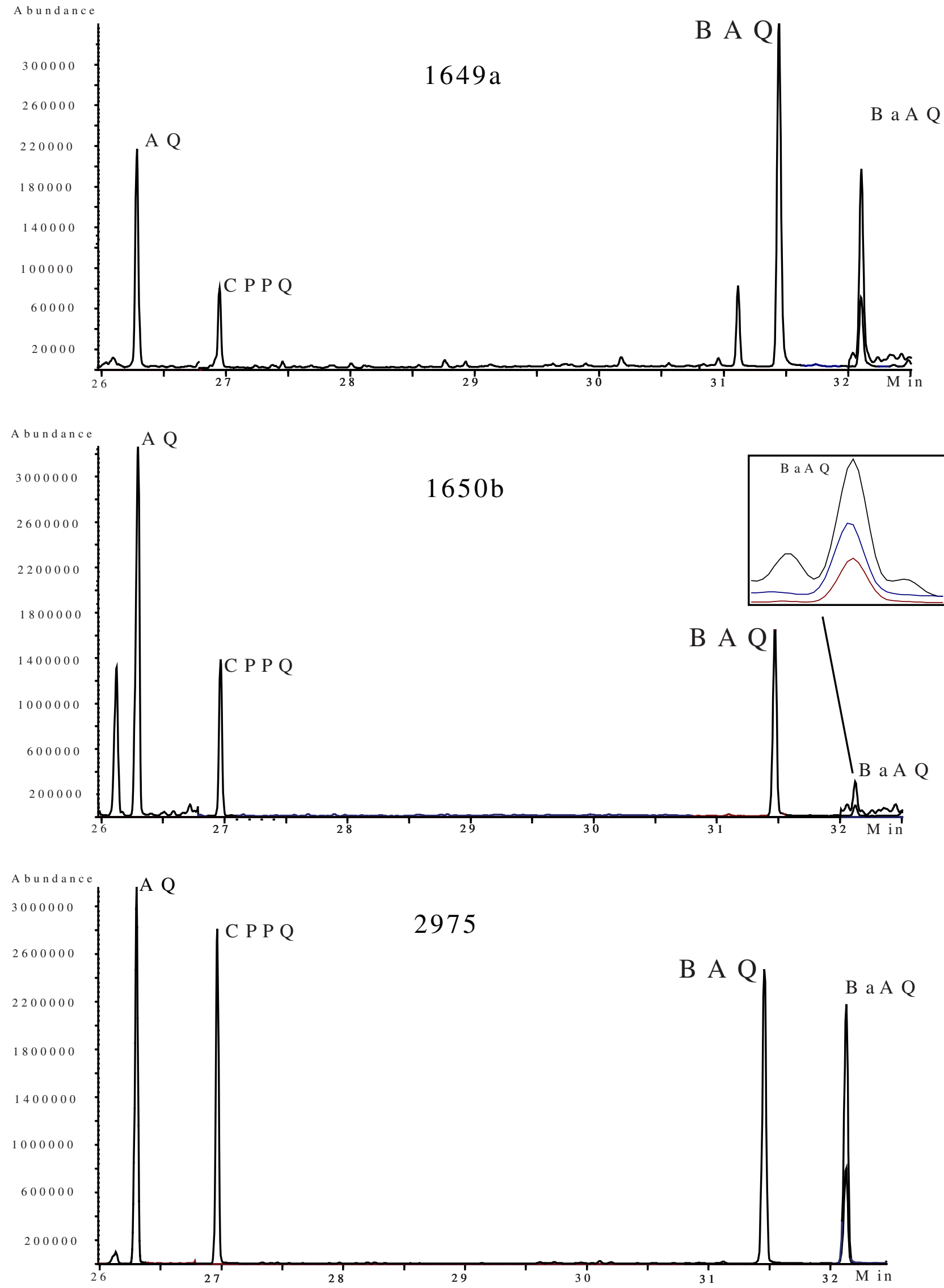

Fig. 1 GC/MS chromatograms (SIM) for the OPAHs in SRM 1649a. SRM 1650b (extracted ions for BaAQ are 258, 230, 222) and SRM 2975 
Table 3 PLE recoveries (mean percentage of three replicate experiments) of standards spiked to glass microfiber filters

\begin{tabular}{lcc}
\hline Quinone standards & $\begin{array}{l}\text { E1 } \\
\text { \% Mean (STD) }\end{array}$ & $\begin{array}{l}\text { E3 } \\
\text { \% Mean (STD) }\end{array}$ \\
\hline AQ & $97.0(12.9)$ & $105.8(0.6)$ \\
4HCPPQ & $110.0(14.6)$ & $105.8(4.7)$ \\
BAQ & $93.1(15.4)$ & $107.6(10.0)$ \\
BaAQ & $67.2(17.5)$ & $84.0(8.9)$ \\
\hline
\end{tabular}

STD standard deviation

and subsequently, toluene was tested and selected as a solvent. An elution volume of $2 \mathrm{ml}$ of toluene was established as satisfactory by incremental additions of $0.5 \mathrm{ml}$ toluene. Using this SPE method gave recoveries above $83 \%$ for the OPAHs in this study, as shown in Table 2.

\section{Method calibration}

The LC-GC/MS system was calibrated using seven-point calibration curves with three replicate injections at each point for all of the OPAHs. The GC/MS peak areas for the five OPAHs increased linearly with the injected amount over the range of $0.7 \mathrm{pg}$ to $43.3 \mathrm{ng}$, displaying an $R^{2} \geq 0.986$ as shown in Table 2.

The instrumental limits of detection (LOD) were established by the stepwise dilution of the standard solutions used as the last points in the calibration curves until peaks having signal to noise ratios $(S / N)$ of $\geq 3$ were achieved, and the limits of quantification (LOQ) were the last points in the calibration curves with $S / N$ of $\geq 10$. Both the LODs and LOQs were calculated by the Agilent ChemStation data analysis software (E.02.02.1431) and are shown in Table 4 together with the reported literature data on the LODs for the analytes.

The LODs for the OPAHs in our work are similar to, equal to, or substantially lower than values reported in previous studies using GC/MS, LC/MS, and LC/MS/MS methodologies (Table 4). The LOD for AQ- $\mathrm{D}_{8}$ is ten times lower than the
LOD for AQ in this present study, and a similar difference in the LODs for these OPAHs can be seen in O'Connell et al. [39]. Albinet and co-workers have reported LODs for OPAHs (including AQ) in the range of 0.01-2.60 pg [23]. The low LODs obtained in their study are most likely a result of operating the MS in the negative ion chemical ionization mode.

Method validation

\section{OPAH levels in SRMs using different PLE conditions}

Different PLE methods (E1, E2, and E3; see Table 1) were used for the extraction of the OPAHs from SRMs 1649a, 1650b, and 2975. SRM 1649a was extracted using extraction protocols E1 and E2 whereas the diesel PM SRMs were extracted using extraction methods E1 and E3. The rationale for this experimental setup was that it has been previously shown that PAHs are more difficult to extract from diesel PM compared to air PM and require high-temperature PLE with long extraction times [35]. In addition, Nocun and Schantz concluded that PLE seems to be a more effective extraction method for the extraction of OPAHs from diesel PM compared to Soxhlet extraction [26]. Our results show that higher values were obtained for all of the OPAHs studied in SRM 1649a using the more-exhaustive extraction method E1 (with $10 \%$ methanol) compared to the data generated by extraction method E2 (Table 5). However, the increase was only significant for AQ using Student's $t$ test at the $5 \%$ probability level ( $p=0.02$, two-sided test, Bonferroni corrected with $n=4$ for the number of analytes tested) as shown in Table 6.

For the diesel PM SRM 1650b, extraction method E3 gave higher mass fractions for AQ and 4CPPQ, while extraction method $\mathrm{E} 1$ gave higher mass fractions for BAQ and BaAQ (Table 7). For SRM 2975, higher concentrations were observed using E1 compared to the less-exhaustive E3 method except for 4CPPQ (Table 8). The observed differences between E1 and E3 were significant for BaAQ in SRM 1650b (mass fraction ratio

Table 4 Instrumental LOD and LOQ in picograms obtained in the present study compared with LOD values from the literature

\begin{tabular}{|c|c|c|c|c|c|c|c|c|}
\hline OPAHs & $\begin{array}{l}\text { LOD, } \\
\text { this } \\
\text { work }\end{array}$ & $\begin{array}{l}\text { LOQ, } \\
\text { this } \\
\text { work }\end{array}$ & $\begin{array}{l}\text { LOD, Walgraeve } \\
\text { et al. [37] }\end{array}$ & $\begin{array}{l}\text { LOD, Layshock } \\
\text { et al. [25] }\end{array}$ & $\begin{array}{l}\text { LOD, Cho et al. } \\
{[44]}\end{array}$ & $\begin{array}{l}\text { LOD, Mirivel } \\
\text { et al. [24] }\end{array}$ & $\begin{array}{l}\text { LOD, Delhomme } \\
\text { et al. [21] }\end{array}$ & $\begin{array}{l}\text { O'Connell et al. } \\
{[39]^{\mathrm{a}}}\end{array}$ \\
\hline AQ-d8 & 0.06 & 0.13 & ND & ND & ND & ND & ND & 0.65 \\
\hline AQ & 0.6 & 1.2 & ND & 5 & 1500 & 10 & 18.4 & 6.9 \\
\hline 4HCPPQ & 0.2 & 0.7 & ND & 1 & ND & ND & ND & 0.21 \\
\hline BAQ & 0.6 & 0.9 & 8 & 10 & ND & 53 & 3.4 & 0.78 \\
\hline $\mathrm{BaAQ}$ & 0.8 & 1.3 & 926 & 10 & ND & 215 & 4 & 0.85 \\
\hline
\end{tabular}

$N D$ no data reported

${ }^{\mathrm{a}} \mathrm{GC} / \mathrm{MS}$ 
Table 5 Mass fractions in nanograms per milligram of SRM 1649a (Urban Dust) determined in the present work ( $n=3$, with standard deviations) compared to data from previous studies

\begin{tabular}{|c|c|c|c|c|c|c|c|c|c|}
\hline OPAHs & This work, E1 & This work, E2 & $\begin{array}{l}\text { Fernandez and } \\
\text { Bayona [45] }\end{array}$ & $\begin{array}{l}\text { Mirivel } \\
\text { et al. [24] }\end{array}$ & $\begin{array}{l}\text { Albinet } \\
\text { et al. [23] }\end{array}$ & $\begin{array}{l}\text { Durant } \\
\text { et al. [46] }\end{array}$ & $\begin{array}{l}\text { Cho } \\
\text { et al. [44] }\end{array}$ & $\begin{array}{l}\text { Sun } \\
\text { et al. [47] }\end{array}$ & $\begin{array}{l}\text { Nocun and } \\
\text { Schantz [26] }\end{array}$ \\
\hline AQ & $3.67(0.23)$ & $3.23(0.027)$ & $2.2(0.04)$ & $2.357(0.183)$ & $2.238(0.363)$ & $2.70(0.12)$ & $2.03(0.192)$ & 2.051 & $1.39(0.16)$ \\
\hline 4HCPPQ & $0.949(0.138)$ & $0.867(0.039)$ & $0.17(0.05)$ & ND & ND & $0.47(0.06)$ & ND & ND & $1.14(0.09)$ \\
\hline BAQ & $5.71(0.25)$ & $4.47(0.52)$ & $1.310(0.02)$ & $4.66(0.460)$ & $3.715(0.872)$ & $4.50(0.34)$ & ND & $2.145(0.128)$ & $3.13(0.40)$ \\
\hline $\mathrm{BaAQ}$ & $5.51(0.40)$ & $5.20(0.80)$ & $7.465(1.1)$ & $3.44(0.322)$ & $8.459(0.797)$ & $2.40(0.25)$ & ND & $5.588(1)$ & $3.75(0.19)$ \\
\hline
\end{tabular}

$N D$ no data reported

$1.0, p=0.002)$ and for all of the OPAHs but BaAQ in SRM 2975 (mass fraction ratios $0.90-1.3, p=0.0005-0.01$ ). Significance was assessed by two-sided $t$ tests with Bonferroni correction $(n=4)$, and the results are shown in Table 6 .

The higher mass fractions obtained using E1 compared to E2 or E3 are likely to be due to the more-exhaustive extraction conditions and/or the use of $10 \%$ methanol in the toluene in E1. The somewhat lower concentrations obtained for 4HCCPQ in the diesel PM SRMs when using extraction method E1 could be a result of degradation.

Interestingly, the obtained PLE recoveries for spiked filters do not reflect the concentrations determined in the SRMs. For example, although not statistically significant (high standard deviations), a higher recovery was obtained for BaAQ when using E3 compared to when using E1, while the opposite was found for SRM 1650b, which yielded a much higher mass fraction when using E1 compared to E3. These types of differences have previously been reported by Lintelmann [20]. The author assumed that the matrix can have a role in deactivation of the active site on the quartz filter, which may stabilize the OPAHs.

\section{Comparison of OPAH concentrations with the literature data}

Data on previously published OPAH concentrations are given in Tables 5, 7, and 8 together with the values generated in the

Table 6 Comparison of the determined OPAHs from the present study by two-sided $t$ tests with Bonferroni correction. The table lists significant differences for comparisons of extraction methods. Single $(+/-)$ and double $(++/-)$ indicate statistically significant differences on the $5 \%$ level without and with Bonferroni correction, respectively. The single plus or minus differences can be seen as an indication of a potential difference, while double plus or minus indicate stronger evidence for a true difference. No symbol indicates that no differences could found

\begin{tabular}{llll}
\hline OPAHs & $1649 \mathrm{a}$ & $1650 \mathrm{~b}$ & 2975 \\
& $\mathrm{E} 1 / \mathrm{E} 2$ & $\mathrm{E} 1 / \mathrm{E} 3$ & $\mathrm{E} 1 / \mathrm{E} 3$ \\
\hline AQ & ++ & & ++ \\
4HCPPQ & & & -- \\
BAQ & & & ++ \\
BaAQ & & ++ & \\
\hline
\end{tabular}

present study. Generally, the concentrations obtained in our study are similar to or higher than the data reported from previous studies. Unfortunately, no certified values have been assigned for these compounds by the NIST in the SRMs tested. A reference value of $15.6 \pm 0.6 \mathrm{ng} / \mathrm{mg}$ exists for 4HCCPQ in SRM 1650b (Table 7), which correlates well with the concentrations generated in the present study, i.e., $14.4 \pm$ $0.9 \mathrm{ng} / \mathrm{mg}$ when extracted using E1 and $17.2 \pm 1.2 \mathrm{ng} / \mathrm{mg}$ when using E3, respectively. In reviewing the literature data from different studies, there are large variations in the reported mass fractions of the four OPAHs (Table 5). The differences could arise from all of the steps of the analytical protocols employed. In a recent study by O'Connell and co-workers [40], they compared the results obtained from analyzing SRM extracts using both GC/MS and LC/MS, and they concluded that the GC-MS method is preferred over the LC-MS method for quantification of the OPAHs.

Apart from using GC/MS or LC/MS, the differences in the mass fractions could arise from the choice of the extraction method (as discussed above) or which internal standard was used for calibration. Only a few isotope-labeled OPAHs are commercially available at the moment, and in some previous studies, isotopelabeled PAHs or nitro PAHs have been used as internal standards [41].

Nocun and Schantz reported differences in the mass fraction obtained for AQ when analyzing air PM SRM extracts using two different GC columns, one $50 \%$ phenyl methylpolysiloxane column (DB-17MS) and one low-polarity column (DB-XLB) [26]. They suggested that the higher values reported in previous studies for AQ and BAQ could be caused by co-elution with other isomers due to the shorter columns that were used with a low-polarity stationary phase and/or faster temperature ramps. The authors concluded that the DB17-MS capillary column is the better choice as it gives less co-elution.

In the present study, a 60-m DB17-MS capillary column was used, and the peak identification of the samples was performed by comparing the area ratios of three fragment ions for each OPAH with those obtained from the standards to reduce the risk of the overestimation of the mass fractions as 
Table 7 Mass fractions in nanograms per milligram of SRM 1650b (Diesel Particulate Matter) determined in the present work ( $n=3$, with standard deviations) compared to data from previous studies

\begin{tabular}{lllllllll}
\hline OPAHs & This work, E1 & This work, E3 & $\begin{array}{l}\text { NIST reference } \\
\text { value [43] }\end{array}$ & $\begin{array}{l}\text { Mirivel } \\
\text { et al. [24] }\end{array}$ & $\begin{array}{l}\text { Layshock } \\
\text { et al. [25] }\end{array}$ & $\begin{array}{l}\text { Nocun and Schantz [26] } \\
\text { O'Connell }\end{array}$ & $\begin{array}{l}\text { O'Connell } \\
\text { et al. [39] }\end{array}$ \\
et al. [39]
\end{tabular}

$N D$ no data reported, $B D L=$ below the detection limit

${ }^{\mathrm{a}} \mathrm{GC} / \mathrm{MS}$

${ }^{b} \mathrm{LC} / \mathrm{MS}$

a result of interfering compounds. The higher amounts of OPAHs found in our study compared to the results presented by Nocun and Schantz are likely a result of other factors such as the extraction method as well as using SPE as a cleanup step.

\section{PAHS}

Aliquots of the same SPE extracts used for the analyses of the OPAHs were injected onto the LC-GC/MS system for quantitative PAH analysis. The results for the PAHs listed as priority PAHs by the EU [41] and the US EPA [42] are presented in Tables 9, 10, and 11 together with the NIST reference/certified values and other data taken from the literature. The mass fractions determined for additional PAHs in the SRM samples are shown in the ESM in Tables S2 to S4. A statistical evaluation of PAH concentrations using the E1, E2, and E3 PLE protocols as well as with NIST and literature data were performed with the two-sided Student's $t$ test. The results are shown in Table 12 for the selected EU/EPA PAHs and in ESM Table 5S for the additional PAHs analyzed.

\section{SRM $1649 a$}

No significant difference was found in the PAH mass fraction when extracting SRM 1649a with E1 and E2 (Tables 9 and 12). Comparing the results from E1 and E2 to the NIST certified/ reference values, significantly higher concentrations were obtained in the present study for Ant and DB[ah]A with E1 and for $\mathrm{B}[\mathrm{k}] \mathrm{F}$ using E2, respectively [31]. The significantly higher values determined for Ant and DB[ah]A could be a result of the extraction method employed in the present work as the data correspond better with the values reported in a recent relevant publication [36], where a higher extraction temperature was found to give increased concentrations of some PAHs such as Ant. Our results show also that the data for the other PAHs correspond well with the data reported by Schantz and coworkers [36], except for $\mathrm{Chr}$ where a significantly higher concentration was obtained (Tables 9 and 12) likely as a result of the chromatographic overlap of $\mathrm{Chr}$ with triphenylene. It should also be mentioned that the concentrations of PAHs in SRM $1649 \mathrm{~b}$ are approximately $5 \%$ lower than in SRM 1649a [43].

\section{SRM $1650 b$}

Tables 10 and 12 show the determined mass fractions for SRM 1650b using PLE methods E1 and E3. The PAHs Ant and Phe showed significantly lower mass fractions with E1 compared to E3, and a possible reason for this difference could be the use of methanol in the extraction solvent in E1. The extractions of this material with E1 and E3 show discrepancies in the results regarding the different PAHs compared to the values assigned by the NIST. However, a significant difference between this study and a study by Schantz and co-workers was only observed for DB[ae]P when similar extraction conditions were used, i.e., Tol:MeOH 9:1. No

Table 8 Mass fractions in nanograms per milligram of SRM 2975 (Diesel Particulate Matter) determined in the present work ( $n=3$, with standard deviations) compared to data from previous studies

\begin{tabular}{lllll}
\hline OPAHs & This work, E1 & This work, E3 & Cochran et al. [40] & Nocun and Schantz [26] \\
\hline AQ & $39.1(0.3)$ & $36.7(0.2)$ & $8.710(0.33)$ & $15.95(2.73)$ \\
4HCPPQ & $20.9(0.3)$ & $24.0(0.4)$ & ND & $19.95(2.51)$ \\
BAQ & $28.5(0.4)$ & $22.2(1.7)$ & ND & $16.28(1.22)$ \\
BaAQ & $41.4(1.5)$ & $38.0(1.9)$ & ND & $21.93(1.96)$ \\
\hline
\end{tabular}

$N D$ no data reported 
Table 9 Mass fractions in nanograms per milligram for SRM 1649a ( $n=3$, with standard deviations) using E1 and E2 methods, certified/reference values for SRM 1649a assigned by NIST and data for SRM 1649b by Schantz

\begin{tabular}{|c|c|c|c|c|c|}
\hline PAHs & Abbreviations & This work, E1 & This work, E2 & NIST [31] & Schantz et al. $[26]^{\mathrm{c}}$ \\
\hline Phenanthrene & Phe & $5.36(0.50)$ & $5.12(0.35)$ & $4.14(0.37)^{\mathrm{a}}$ & $4.354(0.041)$ \\
\hline Anthracene & Ant & $0.809(0.086)$ & $0.841(0.156)$ & $0.432(0.082)^{\mathrm{a}}$ & $0.965(0.008)$ \\
\hline Fluoranthene & Flu & $6.72(0.69)$ & $6.52(0.18)$ & $6.45(0.18)^{\mathrm{a}}$ & $6.571(0.079)$ \\
\hline Pyrene & Pyr & $5.55(0.43)$ & $5.33(0.25)$ & $5.29(0.25)^{\mathrm{a}}$ & $4.969(0.048)$ \\
\hline Benz[a]anthracene & $\mathrm{B}[\mathrm{a}] \mathrm{A}$ & $2.58(0.23)$ & $2.48(0.17)$ & $2.208(0.073)^{\mathrm{a}}$ & $2.268(0.020)$ \\
\hline Chrysene & $\mathrm{Chr}$ & $3.63(0.13)$ & $3.59(0.08)$ & $3.049(0.06)^{\mathrm{a}}$ & $2.988(0.038)$ \\
\hline Benzo[b]fluoranthene & $\mathrm{B}[\mathrm{b}] \mathrm{F}$ & $6.37(0.14)$ & $6.11(0.15)$ & $6.45(0.64)^{\mathrm{a}}$ & $7.760(0.220)^{\mathrm{d}}$ \\
\hline Benzo[k]fluoranthene & $\mathrm{B}[\mathrm{k}] \mathrm{F}$ & $1.82(0.17)$ & $2.14(0.07)$ & $1.913(0.031)^{\mathrm{a}}$ & $1.870(0.10)$ \\
\hline Benzo[a]pyrene & $\mathrm{B}[\mathrm{a}] \mathrm{P}$ & $2.63(0.20)$ & $2.49(0.18)$ & $2.509(0.087)^{\mathrm{a}}$ & $2.970(0.110)$ \\
\hline Indeno[1,2,3-cd]pyrene & $\mathrm{I}[1,2,3-\mathrm{cd}] \mathrm{P}$ & $2.40(0.01)$ & $2.62(0.07)$ & $3.180(0.72)^{\mathrm{a}}$ & $2.678(0.028)$ \\
\hline Dibenz[a,h]anthracene & $\mathrm{DB}[\mathrm{a}, \mathrm{h}] \mathrm{A}$ & $0.534(0.052)$ & $0.326(0.120)$ & $0.288(0.023)^{\mathrm{a}}$ & $0.573(0.013)^{\mathrm{e}}$ \\
\hline Dibenzo[a,l]pyrene & $\mathrm{DB}[\mathrm{al}] \mathrm{P}$ & $0.035(0.019)$ & $0.053(0.022)$ & $0.612(0.0074)^{\mathrm{b}}$ & ND \\
\hline Dibenzo[a,e]pyrene & $\mathrm{DB}[\mathrm{ae}] \mathrm{P}$ & $0.429(0.159)$ & $0.513(0.033)$ & $0.565(0.060)^{\mathrm{a}}$ & $0.622(0.042)$ \\
\hline Dibenzo[a,i]pyrene & $\mathrm{DB}[\mathrm{ai}] \mathrm{P}$ & $0.135(0.035)$ & $0.180(0.034)$ & ND & ND \\
\hline Dibenzo[a,h]pyrene & $\mathrm{DB}[\mathrm{ah}] \mathrm{P}$ & $0.053(0.012)$ & $0.058(0.007)$ & $0.047(0.010)^{\mathrm{a}}$ & ND \\
\hline
\end{tabular}

$N D$ no data reported

${ }^{\text {a }}$ Certified mass fraction for PAHs in SRM 1649a

${ }^{\mathrm{b}}$ Reference mass concentrations for PAHs in SRM 1649a

${ }^{\mathrm{c}}$ Method 8 (parameters in this PLE method are the same as those of E2)

${ }^{\mathrm{d}}$ Sum of $\mathrm{B}[\mathrm{b}] \mathrm{F}$ and $\mathrm{B}[\mathrm{j}] \mathrm{F}$

${ }^{\mathrm{e}}$ Sum of DB[a,c]A and DB[a,h]A

Table 10 Mass fractions in nanograms per milligram for SRM 1650b ( $n=3$, with standard deviations) for the PAHs extracted from $1650 \mathrm{~b}$ using E1 and E3 methods and certified/reference values assigned by NIST and data from the literature

\begin{tabular}{lllllll}
\hline PAHs & This work, E1 & This work, E3 & NIST [32] & Schantz et al. [36] $^{\mathrm{c}}$ & Schantz et al. [36] $^{\mathrm{d}}$ Sadiktsis et al. [34] $^{\mathrm{e}}$ \\
\hline Phe & $65.9(2.3)$ & $79.2(1.4)$ & $69.5(1.9)^{\mathrm{a}}$ & $71.090(0.045)$ & $71.680(1.260)$ & $72.7(1.4)$ \\
Ant & $6.12(0.96)$ & $12.2(0.4)$ & $7.67(0.47)^{\mathrm{a}}$ & $7.47(0.13)$ & $7.450(0.310)$ & $6.79(0.32)$ \\
Flu & $42.0(0.8)$ & $45.6(1.2)$ & $47.3(0.8)^{\mathrm{a}}$ & $50.2(0.50)$ & $50.780(940)$ & $44.0(0.6)$ \\
Pyr & $35.5(1.0)$ & $40.9(1.9)$ & $43.4(1.6)^{\mathrm{a}}$ & $45.90(0.66)$ & $45.120(2.560)$ & $38.1(0.4)$ \\
B[a]A & $7.40(0.28)$ & $7.17(0.11)$ & $6.18(0.30)^{\mathrm{a}}$ & $7.87(0.27)$ & $7.960(0.110)$ & $6.66(0.08)$ \\
Chr & $15.2(0.2)$ & $16.2(0.6)$ & $13.3(1.1)^{\mathrm{a}}$ & $13.76(0.37)$ & $13.130(0.680)$ & $15.9(0.4)$ \\
B[b]F & $8.88(0.65)$ & $7.54(0.42)$ & $6.77(0.84)^{\mathrm{a}}$ & ND & ND & $8.43(0.4)$ \\
B[k]F & $2.69(0.17)$ & $2.25(0.10)$ & $2.37(0.21)^{\mathrm{a}}$ & $2.22(0.07)$ & $2.230(0.046)$ & $2.75(0.07)$ \\
B[a]P & $1.56(0.09)$ & $1.38(0.10)$ & $1.17(0.09)^{\mathrm{a}}$ & $1.68(0.15)$ & $1.680(0.060)$ & $1.40(0.03)$ \\
I[1,2,3-cd]P & $4.15(0.36)$ & $3.66(0.39)$ & $4.44(0.28)^{\mathrm{a}}$ & $4.59(0.07)$ & $4.400(0.230)$ & $3.49(0.23)$ \\
DB[a,h]A & $0.436(0.068)$ & $0.346(0.061)$ & $0.365(0.071)^{\mathrm{a}}$ & ND & ND & $0.586(0.078)$ \\
DB[al]P & $0.061(0.022)$ & $0.037(0.015)$ & $0.137(0.024)^{\mathrm{b}}$ & ND & ND & $0.0178(0.0030)$ \\
DB[ae]P & $0.569(0.071)$ & $0.599(0.059)$ & $1.14(0.12)^{\mathrm{b}}$ & $1.18(0.08)$ & $1.130(0.060)$ & $0.607(0.043)$ \\
DB[ai]P & $0.049(0.014)$ & $0.056(0.007)$ & ND & ND & ND & $0.0470(0.0019)$ \\
DB[ah]P & $0.022(0.004)$ & $0.030(0.003)$ & ND & ND & ND & $0.0229(0.0070)$ \\
\hline
\end{tabular}

$N D$ no data reported

${ }^{a}$ Certified mass fraction for PAHs in SRM 1650b

${ }^{\mathrm{b}}$ Reference concentrations for PAHs in SRM $1650 \mathrm{~b}$

${ }^{\mathrm{c}}$ Method 12 (parameters in this PLE method are the same as those of E3)

${ }^{\mathrm{d}}$ Method 17 (parameters in this PLE method are the same as those of E1)

${ }^{\mathrm{e}}$ PLE parameter the same as that of E1 
Table 11 Mass fractions in nanograms per milligram for SRM 2975 ( $n=3$, with standard deviations) for the PAHs extracted from 2975 with ASE using E1 and E3 and certified/reference values from SRM 2975 assigned by NIST and data from the literature

\begin{tabular}{llllllll}
\hline PAHs & This work, E1 & This work, E3 & NIST [33] & Schantz et al. [36] $^{\mathrm{c}}$ & Schantz et al. [36] $^{\mathrm{d}}$ & Sadiktsis et al. [34] $^{\mathrm{e}}$ & Masala et al. [35] $^{\mathrm{e}}$ \\
\hline Phe & $23.04(0.43)$ & $22.8(0.4)$ & $17.0(2.8)^{\mathrm{a}}$ & $20.8(0.4)$ & $20.510(1.450)$ & $23.7(1.1)$ & ND \\
Ant & $0.798(0.037)$ & $3.38(0.19)$ & $0.038(0.008)^{\mathrm{b}}$ & $0.0486(0.0014)$ & $0.0477(0.0014)$ & $0.661(0.661)$ & ND \\
Flu & $30.8(0.3)$ & $30.7(1.0)$ & $26.6(5.1)^{\mathrm{a}}$ & $31.2(0.5)$ & $31.0(0.320)$ & $30.2(1.4)$ & ND \\
Pyr & $2.03(0.05)$ & $1.86(0.06)$ & $0.90(0.24)^{\mathrm{a}}$ & $1.440(0.05)$ & $1.460(0.040)$ & $2.24(0.13)$ & ND \\
B[a]A & $1.80(0.034)$ & $1.502(0.031)$ & $0.317(0.066)^{\mathrm{a}}$ & $0.956(0.044)$ & $0.988(0.056)$ & $1.89(0.09)$ & ND \\
Chr & $9.75(0.35)$ & $9.23(0.28)$ & $4.56(0.16)^{\mathrm{a}}$ & $5.730(0.05)$ & $5.760(0.280)$ & $10.8(0.6)$ & ND \\
B[b]F & $18.4(0.5)$ & $20.4(2.08)$ & $11.5(3.6)^{\mathrm{b}}$ & ND & ND & $19.7(2.1)$ & $16.80(1.77)$ \\
B[k]F & $1.59(0.09)$ & $1.93(0.19)$ & $0.678(0.076)^{\mathrm{b}}$ & $1.750(0.07)$ & $1.790(0.080)$ & $1.56(0.29)$ & $1.61(0.235)$ \\
B[a]P & $0.803(0.037)$ & $0.657(0.059)$ & $0.052(0.005)$ & $0.773(0.04)$ & $0.770(0.020)$ & $0.919(0.095)$ & $0.870(0.097)$ \\
I[1,2,3-cd]P & $1.82(0.09)$ & $1.98(0.12)$ & $1.4(0.2)^{\mathrm{b}}$ & $2.120(0.11)$ & $2.60(0.120)$ & $1.52(0.17)$ & $1.97(0.213)$ \\
DB[ah]A & $0.218(0.020)$ & $0.250(0.127)$ & $0.52(0.08)^{\mathrm{a}}$ & ND & ND & $0.310(0.053)$ & $0.402(0.043)$ \\
DB[al]P & $0.079(0.014)$ & $0.026(0.012)$ & ND & ND & ND & $0.00611(0.00350)$ & $0.020(0.001)$ \\
DB[ae]P & $0.304(0.057)$ & $0.206(0.026)$ & $0.57^{\mathrm{f}}$ & $0.616(0.032)$ & $0.606(0.033)$ & $0.292(0.038)$ & $0.226(0.034)$ \\
DB[ai]P & $0.056(0.016)$ & $0.049(0.025)$ & ND & ND & ND & $0.0386(0.009)$ & $0.035(0.003)$ \\
DB[ah]P & $0.019(0.003)$ & $0.025(0.009)$ & ND & ND & ND & $0.0275(0.008)$ & $0.017(0.003)$ \\
\hline
\end{tabular}

$N D$ no data reported

${ }^{\text {a }}$ Certified mass fraction for PAHs in SRM 2975

${ }^{\mathrm{b}}$ Reference concentrations for PAHs in SRM 2975

${ }^{\mathrm{c}}$ Method 16 (parameters for this PLE method are the same as those of E3)

${ }^{\mathrm{d}}$ Method 18 (parameters for this PLE method are the same as those of E1

${ }^{\text {e }} 200{ }^{\circ} \mathrm{C}$ with toluene/methanol used for PLE

${ }^{\mathrm{f}}$ Information value

significant differences in the mass fractions of the PAHs (except for $\mathrm{DB}[\mathrm{al}] \mathrm{P}$ ) were found using E1 compared to data from the study by Sadiktsis and co-workers [34], while significant differences were observed for Ant and B[a]A using E3 compared with the data from Sadiktsis et al.

SRM 2975

Tables 11 and 12 show the determined PAH mass fractions using E1 and E3 for SRM 2975. A lower mass fraction could be seen for Ant using E1 compared to E3, which was also observed for the other SRMs. Generally, the extraction methods used in this study gave higher mass fractions compared with the NIST certificate of analysis, except for Flu, Pyr, $\mathrm{B}[\mathrm{k}] \mathrm{F}$, and $\mathrm{DB}[\mathrm{a}, \mathrm{h}] \mathrm{A}$. Interestingly, E1 and E3 gave either significantly higher or lower mass fractions for almost all of the PAHs when compared with the work by Schantz and coworkers [36] although similar extraction conditions were used. No significant difference can be observed between E1 and previously published results from our research group using the same extraction conditions as E1, except for DB[al]P. One of the reasons for the discrepancies between this study and the study by Schantz and co-workers [36] could be due to inhomogeneous particle distribution in different bottles of SRM 2975, which the NIST has stated in the certificate of analysis for this material [33].

\section{Conclusions}

An analytical setup comprising PLE, SPE, and online LCGC/MS for the analysis of OPAHs has been evaluated. The determined LODs for the analyzed OPAHs are generally lower than those previously reported in the literature. The utilization of LVI enables low LODs, which is important in the analysis of OPAHs in low amounts of PM. Furthermore, coupling parts of the analytical protocol online reduces manual labor. By evaluating three different PLE methods for three separate SRMs, it can be concluded that the tested methods were not optimal for the simultaneous analysis of all PAHs and OPAHs in diesel particles. However, good agreement was found for the analysis of PAHs and OPAHs in urban air particles using the two different PLE methods. The variation in the results from this study and data from literature show the importance of the assessment of certified values of OPAHs in these SRMs. 


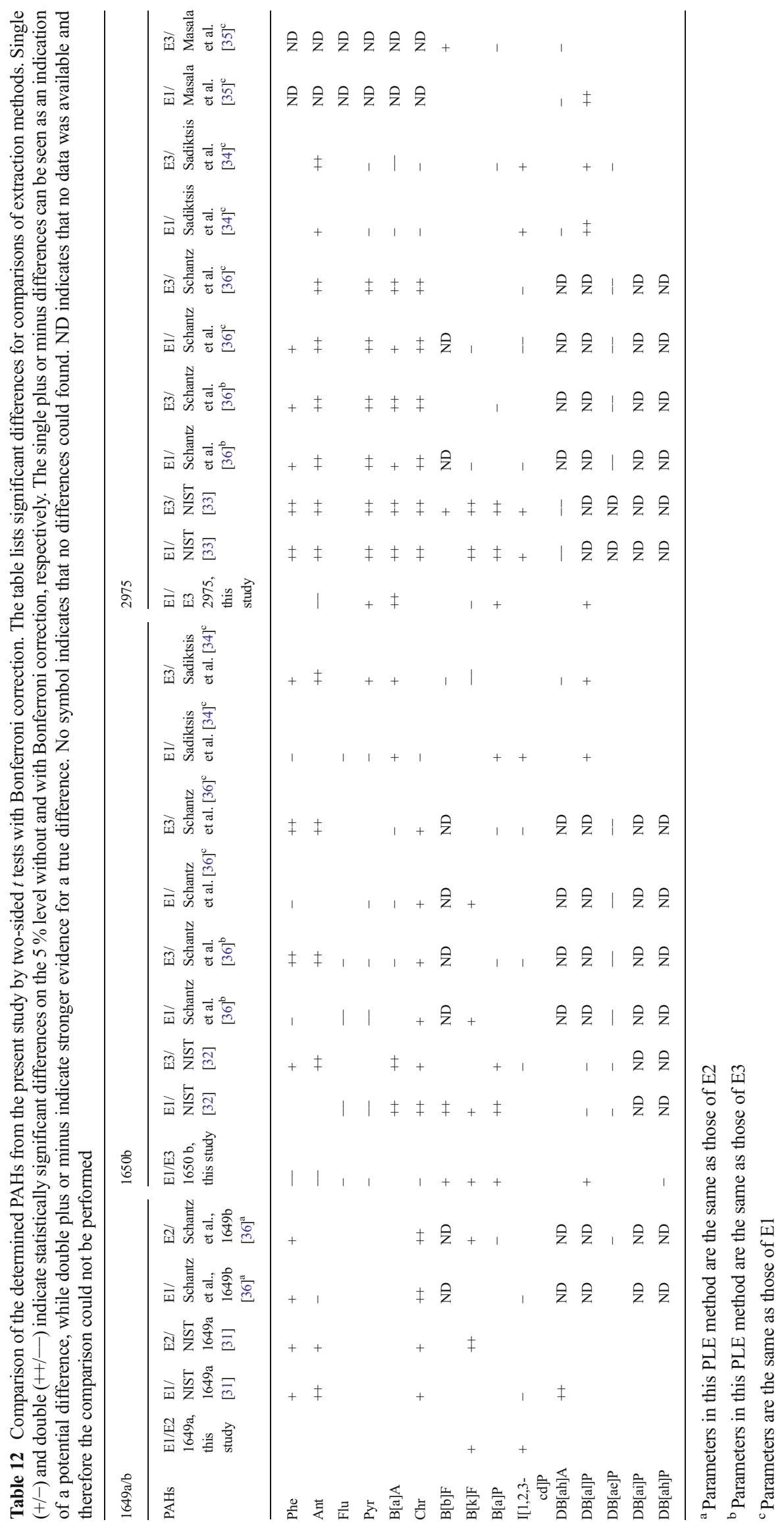


Acknowledgments This study was financed by Stockholm University and the Swedish Research Council.

Open Access This article is distributed under the terms of the Creative Commons Attribution License which permits any use, distribution, and reproduction in any medium, provided the original author(s) and the source are credited.

\section{References}

1. Sehlstedt M, Forsberg B, Westerholm R, Boman C, Sandström T (2007) http://www20.vv.se/fudresultat/Publikationer_000301 000400/Publikation 000310/EMFO201itteraturstudie\% 20Trafikrelaterade $\% 20$ partiklar $\% 20$ och $\% 20 \mathrm{~h} \% \mathrm{C} 3 \%$ A 4 lsoeffekter $\%$ 20-\%20Final\%20report\%20071212.pdf. Accessed July 2014

2. Kunzli N, Kaiser R, Medina S, Studnicka M, Chanel O, Filliger P, Herry M, Horak FJ, Puybonnieux-Texier V, Quenel P, Schneider J, Seethaler R, Vergnaud JC, Sommer H (2000) Lancet 356:795-801

3. Brunekreef B, Holgate ST (2002) Lancet 360:1233-1242

4. See SW, Balasubramanian R, Yang TS, Karthikeyan S (2006) J Toxic Environ Health A 69:1909-1925

5. European Commission (2005) The communication from the commission to the council and the European Parliament on thematic strategy on air pollution and the directive on ambient air quality and cleaner air for Europe, impact assessment. Brussels, September 2005. http://ec.europa.eu/environment/archives/cafe/pdf/ia report en050921 final.pdf. Accessed July 2014

6. Mauderly JL (2001) Toxicol Sci 62:6-9

7. US Environmental Protection Agency (2002) Health assessment document for diesel engine exhaust, EPA/600/8-90/057F. http:// www.epa.gov/ttn/atw/dieselfinal.pdf. Accessed July 2014

8. Singh P, DeMarini DM, Dick CAJ, Tabor DG, Ryan JV, Linak WP (2003) Environ Health Perspect 112:820-825

9. IRAC (2010) Monographs on the evaluation of carcinogenic risks to humans: carbon black, titanium dioxide and talc. International Agency for Research on Cancer, France, Accsessed July 2014

10. Lewtas J (2007) Mutat Res 636:95-133

11. Lundstedt S, White PA, Lemieux CL, Lynes KD, Lambert IB, Oberg L, Haglund P, Tysklind M (2007) Ambio 36:475-485

12. Wang W, Jariyasopit N, Schrlau J, Jia Y, Tao S, Yu TW, Dashwood RH, Zhang W, Wang X, Simonich SL (2011) Environ Sci Technol 45:6887-6895

13. Goldfarb JL, Suuberg EM (2008) Environ Toxicol Chem 27:1244-1249

14. Vione D, Barra S, De Gennaro G, De Rienzo M, Gilardoni S, Perrone MG, Pozzoli L (2004) Ann Chim 94:257-268

15. Eiguren-Fernandez A, Miguel AH, Di Stefano E, Schmitz DA, Cho Ar K, Thurairatnam S, Avol EL, Froines JR (2008) Aerosol Sci Tech 42:854-861

16. Alsberg T, Stenberg U, Westerholm R, Strandell M, Rannug U, Sundvall A, Romert L, Bernson V, Pettersson B, Toftgtird R, Franzqn B, Jansson M, Gustafsson JK, Egebiick KE, Tejle G (1985) Environ Sci Technol 19:43-50

17. Jakober CA, Riddle SG, Robert MA, Destaillats H, Charles MJ, Green PG, Kleeman MJ (2007) Environ Sci Technol 4:4548-4554
18. Walgraeve C, Demeestere K, Dewulf J, Zimmermann R, Van Langenhove H (2010) Atmos Environ 44:1831-1846

19. Harrad SHS, Callén Romero MS, Harrison RM (2003) Atmos Environ 37:4985-4991

20. Lintelmann J, Fischer K, Matuschek G (2006) J Chromatogr A 1133: 241-247

21. Delhomme O, Millet M, Herckes P (2008) Talanta 74:703-710

22. Castells P, Santos FJ, Galceran MT (2003) J Chromatogr A 1010: $141-151$

23. Albinet A, Leoz-Garziandia E, Budzinski H, Viilenave E (2006) J Chromatogr A 1121:106-113

24. Mirivel G, Riffault V, Galloo JC (2010) Anal Bioanal Chem 397: 243-256

25. Layshock JA, Wilson G, Anderson KA (2010) Environ Toxicol Chem 29:2450-2460

26. Nocun MS, Schantz MM (2013) Anal Bioanal Chem 405:5583-5593

27. Kuosmanen K, Hyötyläinen T, Hartonen K, Jönsson JA, Riekkola ML (2003) Anal Bioanal Chem 375:389-399

28. Christensen A, Ostman C, Westerholm R (2005) Anal Bioanal Chem 381:1206-1216

29. Bergvall C, Westerholm R (2006) Anal Bioanal Chem 384:438-447

30. Warner SD, Farant JP, Butler IS (2004) Chemosphere 54:1207-1215

31. NIST (2007) Certificate of analysis. SRM 1649a. Urban dust. National Institute of Standards and Technology, Gaithersburg

32. NIST (2006) Certificate of analysis. SRM1650b. Diesel particulate matter. National Institute of Standards and Technology, Gaithersburg

33. NIST (2009) Certificate of analysis. SRM 2975. Diesel particulate matter (industrial forklift). National Institute of Standards and Technology, Gaithersburg

34. Sadiktsis I, Koegler JH, Benham T, Bergvall C, Westerholm R (2014) Fuel 115:573-580

35. Masala S, Ahmed T, Bergvall C, Westerholm R (2011) Anal Bioanal Chem 401:3305-3315

36. Schantz MM, McGaw E, Wise SA (2012) Anal Chem 84:8222-8231

37. Walgraeve C, Demeestere K, De Wispelaere P, Dewulf J, Lintelmann J, Fischer K, Van Langenhove H (2012) Anal Bioanal Chem 402: $1697-1711$

38. Lintelmann J, Fischer K, Karg E, Schroppel A (2005) Anal Bioanal Chem 381:508-519

39. O'Connell SG, Haigh T, Wilson G, Anderson KA (2013) Anal Bioanal Chem 405:8885-8896

40. Cochran RE, Dongari N, Jeong H, Beranek J, Haddadi S, Shipp J, Kubatova A (2012) Anal Chim Acta 740:93-103

41. European Commission (2005) http://www.fsai.ie/uploadedFiles/ Commission_Recommendation_2005_108_EC.pdf. Accessed July 2014

42. US Environmental Protection Agency (2008) Polycyclic aromatic hydrocarbons http://www.epa.gov/osw/hazard/wastemin/minimize/ factshts/pahs.pdf. Accessed July 2014

43. NIST (2009) Certificate of analysis, SRM 1649b. Urban dust, National Institute of Standards and Technology, Gaithersburg

44. Cho AK, Stefano E, You Y, Rodriguez CE, Schmitz DA, Kumagai Y, Miguel AH, Eiguren-Fernandez A, Kobayashi T, Avol E, Froines JR (2004) Aerosol Sci Technol 38:68-81

45. Fernandez P, Bayona J (1992) J Chromatogr 625:141-149

46. Durant J, Lafleuran A, Plummer E, Taghizadeh K, Busby W, Thilly W (1998) Environ Sci Technol 32:1894-1906

47. Sun Q, Alexandrova OA, Herckes P, Allen JO (2009) Talanta 78: 1115-1121 